\title{
Uma Aproximação dos Conceitos de Subordinação e Vulnerabilidade Análise Comparativa entre o Direito do Trabalho e o Direito do Consumidor
}

\author{
Lúcia Souza d'Aquino \\ Mestre e doutoranda em Direito pela Universidade Federal \\ do Rio Grande do Sul. Membro do Grupo de Pesquisa \\ CNPq "Mercosul, Direito do Consumidor e Globalização". \\ Membro associado do Brasilcon e da International Asso- \\ ciation of Consumer Law. Iucinha@gmail.com
}

\begin{abstract}
Resumo
0 presente artigo tem como finalidade fazer uma análise comparativa entre os conceitos de subordinação no Direito do Trabalho e vulnerabilidade no Direito do Consumidor, verificando a eventual existência de semelhanças e a possibilidade de diálogo entre os institutos. Mediante uma análise do surgimento dos conceitos e sua evolução e positivação em ambos os ramos do Direito, pretende-se aproximá-los, demonstrando a intenção do legislador de, em um Estado Social de Direito, proteger a parte mais fraca nas relações contratuais. A metodologia utilizada é a dialética, utilizando também os métodos histórico e comparativo.
\end{abstract}

Palavras-chave: Subordinação. Vulnerabilidade. Direito do Trabalho. Direito do Consumidor. Diálogo de fontes. 


\title{
An Approach Between the Concepts of Subordination and Vulnerability: comparative analysis between Labour Law and Consumer Law
}

\begin{abstract}
This paper intends to make a comparative analysis between the concepts of subordination on Labor Law and vulnerability on Consumer Law, verifying the existence of similitude and the possibility of a dialogue between the institutes. Through an analysis of the rising of those concepts and their evolution and affirmation in both fields of law, it has the intention to approximate them, showing the lawmaker's intention of, in a Social Rule of Law, protect the weaker part in contractual relations. The research methodology is dialectical, also utilizing the historical and comparative methods.
\end{abstract}

Keywords: Subordination. Vulnerability. Labor Law. Consumer Law. Dialogue of sources.

Sumário: 1 Introdução. 2 A subordinação no Direito do Trabalho: evolução histórica. 2.1 Subordinação econômica. 2.2 Dependência social. 2.3 Subordinação técnica. 2.4 A necessidade de revisão da subordinação. 3 A vulnerabilidade no Direito do Consumidor. 4 Necessidade de diálogo entre 0 Direito do Trabalho e o Direito do Consumidor. 5 Considerações finais. 6 Referências. 


\section{INTRODUÇÃO}

O Direito do Trabalho surgiu em um contexto em que o mundo em desenvolvimento saía do escravagismo em direção ao trabalho livre. Por essa razão, e porque os trabalhadores àquela época eram substancialmente mais vulneráveis aos seus patrões, era necessário um direito protetivo, abrangente, que abrangesse o maior número possível de trabalhadores para garantir-lhes uma existência digna por meio do trabalho.

Com a evolução da sociedade, das técnicas de trabalho e também do acesso à informação, atualmente os trabalhadores têm melhores condições de vida e de exercício de sua profissão.

Essa evolução trouxe consigo também a modificação de todas as relações, inclusive as de trabalho. Atualmente vê-se cada vez mais formas de prestação de serviço.

O Direito do Trabalho, entretanto, não parece ter acompanhado essa evolução na mesma velocidade. Desde o seu surgimento, o principal requisito para o reconhecimento de vínculo empregatício é a subordinação, cujo conceito remete à hierarquia entre as partes.

Já em 1978, Romita visualizava “a idéia segundo a qual o Direito do Trabalho deve expandir-se para abranger outras formas de relação de trabalho, que não sejam apenas as de trabalho subordinado,"1 demonstrando que as alterações nas relações de trabalho tornam necessária a ampliação de seus conceitos e pressupostos.

Em outro ramo do Direito, este mais novo, encontra-se situação que pode ser considerada análoga. O Direito do Consumidor, no Brasil, surgiu após a Constituição de 1988, com a necessidade de proteger a parte mais

${ }^{1}$ ROMITA, Arion Sayão. Conceito objetivo de subordinação. Arquivos do Ministério da Justiça. Rio de Janeiro, ano 35, n. 148, out./dez. 1978. p. 75. 
fraca na relação de consumo. Nascido a partir do mandamento constitucional do artigo 48 do Ato das Disposições Constitucionais Transitórias, ${ }^{2}$ a lei consumerista visa a reequilibrar a balança das relações de consumo.

Desde o seu surgimento, o Código de Defesa do Consumidor ressalta a vulnerabilidade do consumidor diante do fornecedor, sendo o reconhecimento dessa condição princípio explícito da Política Nacional das Relações de Consumo. ${ }^{3} \mathrm{Na}$ contramão do Direito do Trabalho, entretanto, o conceito de vulnerabilidade tem se expandido, a fim de abarcar cada vez mais relações.

O presente estudo traçará um paralelo entre a evolução dos dois conceitos - subordinação e vulnerabilidade - a fim de verificar se é necessário, ou sequer possível, uma aproximação proveitosa.

A importância do estudo a ser desenvolvido reside no fato de que ambos os ramos do Direito, apesar de surgidos em épocas distintas, têm como objetivo principal proteger a parte que, em razão das mudanças ocorridas nos últimos séculos na sociedade e no Direito, tornaram-se mais fracas em relação a seus contratantes, demonstrando a preocupação do Estado Social, centrado na pessoa humana, em reequilibrar tais situações.

Diante dos atuais e acirrados debates a respeito de flexibilização em tais ramos do Direito, torna-se de extrema importância remontar as suas origens e aproximá-los, demonstrando sua razão de ser e sua importância atual no ordenamento jurídico.

\footnotetext{
${ }^{2}$ Artigo 48. O Congresso Nacional, dentro de 120 dias da promulgação da Constituição, elaborará Código de Defesa do Consumidor. (Elaborado o Código de Defesa do Consumidor - Lei n. 8.078 de 11 de setembro de 1990 -, este entrou em vigor 180 dias após sua publicação).

${ }^{3}$ Artigo $4^{\circ}$. A Política Nacional das Relações de Consumo tem por objetivo o atendimento das necessidades dos consumidores, o respeito à sua dignidade, saúde e segurança, a proteção de seus interesses econômicos, a melhoria da sua qualidade de vida, bem como a transparência e harmonia das relações de consumo, atendidos os seguintes princípios:I - reconhecimento da vulnerabilidade do consumidor no mercado de consumo; (...)
} 
Por meio do método dialético, trata-se da relação e conexão entre os conceitos e suas origens na sociedade, eis que "os fatos sociais não podem ser entendidos quando considerados isoladamente, abstraídos de suas influências políticas, econômicas, culturais”. ${ }^{4} \mathrm{O}$ método histórico auxiliará na demonstração das influências dos acontecimentos dos últimos séculos na sociedade e seus reflexos no Direito, ao passo em que o método comparativo vem demonstrar as similaridades entre ambos os ramos do Direito e entre os conceitos aqui estudados.

\section{A SUBORDINAÇÃO NO DIREITO DO TRABALHO: EVOLUÇÃO HISTÓRICA}

A subordinação ou dependência é apontada como índice inequívoco na existência de contrato de trabalho, ${ }^{5}$ ou a "mais evidente manifestação da existência de um contrato de emprego", 6 eis que o Direito brasileiro só admite a existência de contrato de trabalho quando houver subordinação, ou seja, trabalho prestado sob dependência do empregador. Nascimento aponta a origem do termo, que provém de $s u b$ (baixo) e ordinare (ordenar), ou seja, "submetimento, sujeição o poder de outrem, à ordens de terceiros, uma posição de dependência”.

${ }^{4}$ GIL, Antônio Carlos. Métodos e técnicas de pesquisa social. 6. ed. São Paulo: Atlas, 2008. p. 14.

${ }^{5}$ Nesse sentido, entre outros: LEITE, Carlos Henrique Bezerra. Curso de Direito do Trabalho. 6. ed. São Paulo: Saraiva, 2015. p. 150; NASCIMENTO, Amauri Mascaro. Curso de direito do trabalho: história e teoria geral do direito do trabalho: relações individuais e coletivas do trabalho. 13. ed. São Paulo: Saraiva, 1997. p. 313; SÜSSEKIND, Arnaldo et al. Instituições de direito do trabalho. v. 1. 21. ed. São Paulo: LTr, 2003. p. 167.

${ }^{6}$ CARRION, Valentin. Comentários à consolidação das leis trabalhistas. 40. ed. São Paulo: Saraiva, 2015. p. 48.

${ }^{7}$ NASCIMENTO, Amauri Mascaro. Curso de direito do trabalho: história e teoria geral do direito do trabalho: relações individuais e coletivas do trabalho. 13. ed. São Paulo: Saraiva, 1997. p. 388. 
Gomes defende que somente o trabalho subordinado poderia ser tutelado pelo Direito do Trabalho:

O direito do trabalho deve ser unicamente um conjunto de regras concernentes ao trabalho subordinado, um dos mais importantes fenômenos da organização social e econômica dos nossos dias. Ao seu âmbito normativo são realmente estranhas todas as formas jurídicas do trabalho humano, nas quais este não se realiza sob a direção de quem o remunera. Pode-se levar a depuração até o extremo de excluir da sua estrutura os trabalhadores dependentes, que não exercem sua atividade a serviço de uma empresa. ${ }^{8}$

$\mathrm{O}$ artigo $3^{\circ}$ da Consolidação das Leis do Trabalho, ${ }^{9}$ em sua redação, faz clara menção ao trabalho subordinado, quando menciona "sob a dependência deste" (do empregador).

A dependência referida diz respeito à hierarquia existente entre trabalhador e empregador. Tanto é assim que foi apontado como contraponto à subordinação o poder de comando. ${ }^{10}$ de um lado, o empregado, subordinado, acata ordens; de outro o empregador, com poder de comando, dirige a atividade empresarial.

A dependência do prestador com ofertante de trabalho é elemento essencial ao contrato individual de trabalho. Apesar de doutrina e jurisprudência serem unânimes a esse respeito, não o eram quanto ao conceito de dependência. Havia entendimentos de que fosse estado de subordinação, dependência econômica, reduzindo ambas a conceito de dependência social; outros optavam por subordinação aliada (ou não) à dependência; havia, ainda, quem distinguisse subordinação jurídica e técnica, não se

${ }^{8}$ GOMES, Orlando. Questões de direito do trabalho. São Paulo: LTr, 1974. p. 208.

${ }^{9}$ Artigo $3^{\circ}$ - Considera-se empregado toda pessoa física que prestar serviços de natureza não eventual a empregador, sob a dependência deste e mediante salário.

${ }^{10}$ CARRION, Valentin. Comentários à Consolidação das Leis Trabalhistas. 40. ed. São Paulo: Saraiva, 2015. p. 48. 
conseguindo muitas vezes concluir qual delas era a correta ${ }^{11}$. O pacto entre empregadores e assalariados é o contrato de trabalho. A relação entre eles não é de igual para igual, de onde deriva a sujeição de uns aos outros. Essa sujeição determinou a proteção mediante normas que têm como característico o estabelecimento de uma superioridade jurídica para compensar a inferioridade econômica do trabalhador.

Essa inferioridade era denominada por Lacerda ${ }^{12}$ como dependência, conceito para ele diferente de subordinação. Para este autor, era fundamental a diferenciação entre trabalho autônomo e subordinado. A dependência de que se fala quando diferencia trabalho autônomo e dependente não pode definir apenas subordinação jurídica.

Segundo Barassi, ${ }^{13}$ o estado de subordinação deveria se concretizar numa dependência hierárquica e disciplinar, de maneira a vincular a atividade do prestador às iniciativas e às ordens do empregador. Oliveira Vianna, ${ }^{14}$ por sua vez, definia: subordinação é o poder que tem alguém, por força do contrato, de dar ordens, de comandar, de dirigir a atividade de outrem. No momento em que o trabalhador fica obrigado a receber ordens daquele a quem o serviço é prestado, está em situação de subordinação, objetivando-se numa situação de superioridade hierárquica deste para com aquele.

\footnotetext{
${ }^{11}$ NASCIMENTO, Amauri Mascaro. Curso de direito do trabalho: história e teoria geral do direito do trabalho: relações individuais e coletivas do trabalho. 13. ed. São Paulo: Saraiva, 1997. p. 388.

${ }^{12}$ LACERDA, Dorval de. A renúncia no direito do trabalho. 2. ed. São Paulo: Max Limonad, 1944.

${ }^{13}$ BARASSI, Ludovico. Tratado de derecho del trabalho. Buenos Aires: Editorial Alfa, 1953. p. 151.

${ }^{14}$ OLIVEIRA VIANNA, José Francisco de. Contratos de trabalho, de empreitada e de mandato. Boletim do Ministério do Trabalho, Industria e Commercio. Rio de Janeiro, n.33/34, maio/jun. 1937.
} 
E distinguia subordinação jurídica e técnica: subordinação jurídica é estado de dependência real, decorrente do direito do empregador de dar ordens, gerando a obrigação correspondente do empregado de se submeter a elas; é o direito geral de fiscalizar o trabalho de outrem. Direção e fiscalização são os polos da subordinação jurídica. Subordinação técnica, por sua vez, importa em direção a dar ao trabalho do empregado, provinda de um técnico. ${ }^{15}$

\subsection{Subordinação econômica}

A razão da subordinação do trabalhador ao empregador é a necessidade da boa organização e da boa exploração da empresa, segundo Lacerda. ${ }^{16}$

Gomes ${ }^{17}$ por seu turno, entendia que a subordinação jurídica manifestava-se em duas obrigações: horário (empregador delimita o serviço no tempo, determinando horário, período de repouso, interrupções de trabalho) e fiscalização (ordens ditadas pelo patrão).

Há o entendimento de que a subordinação pode ser jurídica, econômica, técnica ou social. A jurisprudência brasileira filia-se à jurídica, que se traduz no poder de dar ordens e dever de se submeter a elas.

A subordinação como único elemento diferenciador do contrato de trabalho gerava confusões e injustiças, pois não é um conceito completo. Por essa razão, a doutrina e a jurisprudência alemãs passaram a admitir

\footnotetext{
${ }^{15}$ OLIVEIRA VIANNA, José Francisco de. Contratos de trabalho, de empreitada e de mandato. Boletim do Ministério do Trabalho, Industria e Commercio. Rio de Janeiro, n.33/34, maio/jun. 1937.

${ }^{16}$ LACERDA, Dorval de. A renúncia no direito do trabalho. 2. ed. São Paulo: Max Limonad, 1944. p. 12.

${ }^{17}$ GOMES, Orlando apud LACERDA, Dorval de. A renúncia no direito do trabalho. 2. ed. São Paulo: Max Limonad, 1944.
} 
também como elemento caracterizador do contrato de trabalho a subordinação econômica ou, mais precisamente, a dependência econômica. E foi além a jurisprudência, fazendo da subordinação econômica a condição geradora do dever de subordinação jurídica. ${ }^{18}$

A legislação portuguesa também era muito rígida, e a subordinação jurídica como critério era exclusivista e excluía muitas formas de trabalho da proteção legal, razão pela qual atualmente é levada em conta a dependência econômica para a conceituação da subordinação. ${ }^{19}$

A legislação brasileira utiliza a expressão dependência, nela englobada subordinação jurídica e econômica.

Cuche $^{20}$ argumenta que são necessárias duas condições para que haja dependência econômica: que o trabalhador tire do trabalho seu único ou principal meio de subsistência e que o patrão absorva integralmente e regularmente a atividade do trabalhador. É necessário que tome todo o tempo do prestador, não existindo a possibilidade de este oferecer seus serviços a outros empregadores.

Alguns autores resistem ao critério da dependência econômica. Fantini ${ }^{21}$ expressa que há uma zona marginal entre o trabalho autônomo e o subordinado, na qual estão incluídos os trabalhos a domicílio e de aprendizagem, terminando por lhes dar a proteção conferida aos contratos

\footnotetext{
${ }^{18}$ SILVA, Antônio Álvares da. Convenção Coletiva do Trabalho perante o Direito Alemão. Rio de Janeiro: Forense, 1981, p. 199.

${ }^{19}$ ABRANTES, José João. Estudo sobre o Código do Trabalho. Coimbra: Coimbra Editora, 2004. p. 94 .

${ }^{20}$ CUCHE, Paul apud LACERDA, Dorval de. A renúncia no direito do trabalho. 2. ed. São Paulo: Max Limonad, 1944. p. 24.

${ }^{21}$ FANTINI, Oddone. Legislazione Corporativa del Lavoro. Milano: Francesco Vallardi, 1938. p. 77.
} 
de trabalho. Barassi, ${ }^{22}$ por sua vez, considera ser possível estender a um trabalhador autônomo (no caso, a domicílio), a proteção do Direito do Trabalho.

No Brasil também há quem se filie ao critério da subordinação, exclusivamente, como Cesarino Junior. ${ }^{23}$ Ele defende que há diversos casos em que há dependência econômica (pequeno industrial, comerciante ou agricultor em relação aos grandes capitalistas; filho em relação ao pai; esposa sem bens em relação ao marido, etc.) sem que haja necessariamente uma relação de trabalho. Dorval de Lacerda ${ }^{24}$ afirma que o argumento é inconsistente, eis que também pode haver subordinação sem que haja relação de trabalho.

La Cueva ${ }^{25}$ nega o conceito de dependência econômica para caracterizar o contrato de trabalho. Por adotar conceito que deriva da dicotomia capital e trabalho, subordinação já inclui dependência econômica.

Pelo exposto, não há dúvidas de que a subordinação jurídica e a dependência econômica, quando existentes num contrato de prestação de serviços, configuram-no como contrato de trabalho. Não precisam coexistir, basta que existam.

Como exemplo de dependência sem subordinação existem os profissionais liberais, e como exemplo de subordinação sem dependência estão os empregados “de cozinha ou arrumação” (geralmente contratam

${ }^{22}$ BARASSI, Ludovico. Tratado de derecho del trabalho. Buenos Aires: Editorial Alfa, 1953. p. 161.

${ }^{23}$ CESARINO JUNIOR, Antonio Ferreira. Natureza jurídica do contrato individual de trabalho. Rio de Janeiro: A. Coelho Branco, 1938.

${ }^{24}$ LACERDA, Dorval de. A renúncia no direito do trabalho. 2. ed. São Paulo: Max Limonad, 1944. p. 30-32.

${ }^{25}$ LA CUEVA, Mario de. Derecho mexicano del trabajo. 4. ed. México: Editorial Porrua, 1954. Tomo I. 
com vários, não dependem economicamente de nenhum, mas do conjunto, pois o que recebem de cada um é sua única ou mais preponderante parcela de meio de subsistência).

\subsection{Dependência social}

Savatier ${ }^{26}$ foi o primeiro a propor a expressão para caracterizar o contrato de trabalho, mas ela não é um critério novo, e sim uma fusão dos elementos tradicionais.

A dependência econômica está quase sempre acompanhada de subordinação, e nesse caso não há por que não utilizar a denominação de dependência social. Não havendo um dos elementos, porém, haveria dificuldade na caracterização. Por isso, dependência social aumenta dificuldades num caso já por si mesmo difícil.

\subsection{Subordinação técnica}

Colin ${ }^{27}$ entende ser um vínculo que surge entre indivíduos, que exercem de modo constante uma especialidade da indústria humana e para o exercício da qual servem-se de outros. Como elemento de determinação do contrato de trabalho, no entanto, a noção era repelida pela jurisprudência, pois para que houvesse subordinação, dar ordens era o bastante, não sendo necessário que fossem ordens técnicas.

\footnotetext{
${ }^{26}$ SAVATIER apud LACERDA, Dorval de. A renúncia no direito do trabalho. 2. ed. São Paulo: Max Limonad, 1944. p. 35.

${ }^{27}$ COLIN, Paul apud LACERDA, Dorval de. A renúncia no direito do trabalho. 2. ed. São Paulo: Max Limonad, 1944. p. 40.
} 
A subordinação é exigência técnica e funcional da empresa. Ela existe quando modalidades da prestação de trabalho são determinadas pelo empresário e devem ser seguidas pelos trabalhadores. A organização da empresa exige ação de comando continuativa e centralizada na pessoa do empregador, à qual se subordinam todos os dependentes (trabalhadores subordinados).

Ela consiste na integração da atividade do trabalhador na organização da empresa, mediante vínculo contratualmente estabelecido, em virtude do qual o empregado aceita determinação das modalidades de prestação de trabalho.

Romita aponta para as consequências da aceitação do critério objetivo de subordinação, consistente "na integração da atividade do trabalhador na organização da empresa, mediante um vínculo contratualmente estabelecido, em virtude do qual o empregado aceita a determinação, pelo empregador, das modalidades de prestação de trabalho.”28

São elas: a subordinação não é status do trabalhador, mas de sua atividade; não significa sujeição ou submissão pessoal; não exige a atuação da vontade do empregador na esfera jurídica do empregado, basta a possibilidade dessa atuação. ${ }^{29}$

Esses foram os conceitos basilares de subordinação no âmbito do Direito do Trabalho. Desde seu surgimento, foram se estreitando, de forma que o panorama atual é de que o trabalho tutelado pelo Direito do Trabalho é apenas aquele exercido sob condição de subordinação típica, em que o empregador exerce seu poder diretivo sobre o empregado.

${ }^{28}$ ROMITA, Arion Sayão. Conceito objetivo de subordinação. Arquivos do Ministério da Justiça, Rio de Janeiro, ano 35, n. 148, out./dez. 1978. p. 85.

${ }^{29}$ ROMITA, Arion Sayão. Conceito objetivo de subordinação. Arquivos do Ministério da Justiça, Rio de Janeiro, ano 35, n. 148, out./dez. 1978. p. 85. 


\subsection{A necessidade de revisão da subordinação}

O contexto atual mostra a necessidade de revisão do conceito de subordinação, que ficou estrito demais, deixando de fora da proteção trabalhista novas formas de trabalho que surgiram com o desenvolvimento das relações, bem como novos artifícios utilizados para escapar à legislação trabalhista.

Entre as novas configurações que exigem a revisão do conceito de subordinação estão a terceirização crescente, a "pejotização" 30 no âmbito das relações de trabalho, o trabalho à distância e em domicílio, o trabalho autônomo, entre outros. Ainda que esses casos comecem a ser abordados pela jurisprudência, faz-se necessária uma revisão doutrinária e legislativa, a fim de colocar ao abrigo da lei aqueles que, necessitados de algum trabalho, sujeitam-se a situações fictícias (no caso, por exemplo, da pejotização) a fim de terem algum trabalho. Nesses casos, o trabalho é prestado à margem do Direito do Trabalho, privando o trabalhador, parte mais fraca da relação, da proteção legal e dos benefícios obtidos pela relação formal de trabalho.

Pelos novos rumos tomados pelas relações de trabalho, um número cada vez maior de trabalhadores, vulneráveis, que necessitam de proteção, não as tem recebido.

\footnotetext{
${ }^{30}$ O termo "pejotização", derivado da sigla utilizada para abreviar a expressão Pessoa Jurídica (PJ), consiste no mecanismo por meio do qual o empregador, com a finalidade de burlar a legislação trabalhista, exige que o empregado constitua uma empresa para a sua admissão ou manutenção no emprego, descaracterizando, assim, a relação de emprego (STANDER, Célia Regina Camachi. Fraude por meio de cooperativa e de constituição de pessoa jurídica por trabalhadores. Revista da Escola da Magistratura do Tribunal Regional do Trabalho da $2^{\underline{a}}$ Região, São Paulo, a. I, n. 1, p. 105, set. 2006.)
} 
O Direito do Trabalho, nos moldes que se põe na atualidade, tem restringido cada vez mais o seu campo de proteção, por não acompanhar as modificações da sociedade pós-fordista. ${ }^{31}$ É necessário, portanto, que se reveja o conceito de subordinação e sua utilização como critério máximo de verificação da existência de relação de trabalho.

\section{A VULNERABILIDADE NO DIREITO DO CONSUMIDOR}

Outro ramo do Direito que tem como finalidade assegurar a tentativa de igualar os desiguais, protegendo a parte frágil da relação, é o Direito do Consumidor.

O Código de Defesa do Consumidor surgiu em decorrência de determinação contida no artigo 48 do Ato das Disposições Constitucionais Transitórias, com a finalidade de viabilizar as disposições constitucionais de defesa do consumidor.

Em seu artigo $4^{\circ}$, I, consagra a vulnerabilidade do consumidor:

Art. 4º A Política Nacional das Relações de Consumo tem por objetivo $\mathrm{o}$ atendimento das necessidades dos consumidores, o respeito à sua dignidade, saúde e segurança, a proteção de seus interesses econômicos, a melhoria da sua qualidade de vida, bem como a transparência e harmonia das relações de consumo, atendidos os seguintes princípios: I - reconhecimento da vulnerabilidade do consumidor no mercado de consumo; (...)

${ }^{31}$ ASSIS, Rui de. O poder de direcção do empregador: configuração geral e problemas actuais. Coimbra: Coimbra Editora, 2005; ROSANVALLON, Pierre. La société des égaux. Paris: Seuil, 2011. 
Desde o surgimento do Código, doutrina e jurisprudência vêm tentando interpretar o conceito de vulnerabilidade a fim de outorgar proteção máxima ao consumidor.

O conceito de vulnerabilidade, desde que sancionada a lei, vem sendo formulado e reformulado, a fim de atingir o maior número possível de consumidores, dando a eles proteção máxima em suas relações de consumo.

Moraes, em obra que trata especificamente do princípio de vulnerabilidade, propõe o seguinte conceito:

Vulnerabilidade, sob o enfoque jurídico, é, então, o princípio pelo qual o sistema jurídico positivado brasileiro reconhece a qualidade ou condição daquele(s) sujeito(s) mais fraco(s) na relação de consumo, tendo em vista a possibilidade de que venha(m) a ser ofendido(s) ou ferido(s), na sua incolumidade física ou psíquica, bem como no âmbito econômico, por parte do(s) sujeito(s) mais potente(s) da mesma relação. ${ }^{32}$

Marques, tratando do tema, aborda a evolução da interpretação do conceito de vulnerabilidade, demonstrando a ampliação do conceito, antes aplicável com muitas ressalvas a pessoas jurídicas.

É uma interpretação finalista mais aprofundada e madura, que deve ser saudada. Em casos difíceis envolvendo pequenas empresas que utilizam insumos para a sua produção, mas não em sua área de expertise ou com uma utilização mista, principalmente na área dos serviços, provada a vulnerabilidade, concluiu-se pela destinação final de consumo prevalente. Esta nova linha, em especial do STJ, tem utilizado, sob o critério finalista e subjetivo, expressamente a equiparação do art. 29 do CDC, se tratando de pessoa jurídica que comprove ser vulnerável

${ }^{32}$ MORAES, Paulo Valério Dal Pai. Código de defesa do consumidor: o princípio da vulnerabilidade no contrato, na publicidade, nas demais práticas comerciais: interpretação sistemática do direito. Porto Alegre: Livraria do Advogado, 2009. p. 125. 
e atue fora do âmbito de sua especialidade, como hotel que compra gás. Isso porque o $\mathrm{CDC}$ conhece outras definições de consumidor. $\mathrm{O}$ conceito-chave aqui é o de vulnerabilidade..$^{33}$

Há que se atentar, entretanto, para não confundir vulnerabilidade e hipossuficiência, como alerta a melhor doutrina:

A vulnerabilidade, que não se confunde com hipossuficiência, vai além de mero reflexo de desigualdade econômica, existente, de regra, entre empresário e adquirente final dos produtos e serviços. Abrange outros aspectos, como a carência e informações sobre os bens e produtos cada vez mais complexos, a existência de manobras entre empresários para fraudar a livre concorrência e impor ao consumidor produtos caros e sem a qualidade desejada, a utilização de sofisticados procedimentos de marketing que, antes de informar, criam a necessidade de consumir. ${ }^{34}$

\section{Grinover também ressalta essa distinção:}

[A] vulnerabilidade é um traço universal de todos os consumidores, ricos ou pobres, educados ou ignorantes, crédulos ou espertos. Já a hipossuficiência é marca pessoal, limitada a alguns - até mesmo a uma coletividade - mas nunca a todos os consumidores. A vulnerabilidade do consumidor justifica a existência do Código. A hipossuficiência, por seu turno, legitima alguns tratamentos diferenciados no interior do próprio Código como, por exemplo, a previsão de inversão do ônus da prova (art. $6^{\circ}$, VIII) ${ }^{35}$

\footnotetext{
${ }^{33}$ BENJAMIN, Antônio Herman V.; MARQUES, Claudia Lima; BESSA, Leonardo Roscoe. Manual de direito do consumidor. 4. ed. São Paulo: Revista dos Tribunais, 2012. p. 92-93.

${ }^{34} \mathrm{BESSA}$, Leonardo Roscoe. Aplicação do código de defesa do consumidor: análise crítica da relação de consumo. Brasília: Brasília Jurídica, 2007. p. 39.

${ }^{35}$ GRINOVER, Ada Pellegrini; et. al. Código Brasileiro de Defesa do Consumidor: comentado pelos autores do anteprojeto. 6. ed. Rio de Janeiro: Forense Universitária, 2000. p. 313-314.
} 
Miragem também sustenta a distinção, afirmando ser a hipossuficiência um critério de "avaliação judicial para a decisão sobre a possibilidade ou não de inversão do ônus da prova em favor do consumidor”, ao passo que a vulnerabilidade deriva do fato de que os consumidores "não possuem o poder de direção da relação de consumo, estando expostos às práticas comerciais dos fornecedores no mercado". ${ }^{36}$ Surgem, por outro lado, teorias dividindo a vulnerabilidade em vários aspectos, que têm particular utilidade na análise comparada que será feita posteriormente.

Moraes $^{37}$ apresenta uma divisão da vulnerabilidade ampla, em que há sete espécies, que serão a seguir resumidas.

A vulnerabilidade técnica é aquela que decorre da ausência de conhecimento sobre os meios utilizados para elaborar produtos ou para conceber serviços, tampouco sobre seus efeitos. Segundo o autor, os principais motivos para a vulnerabilidade técnica são a falta de informação, informações prestadas incorretamente e mesmo o excesso de informações desnecessárias.

Jurídica é a vulnerabilidade decorrente da avaliação das dificuldades que o consumidor possui para defender seus direitos.

Já a vulnerabilidade política ocorre em razão da fraqueza do consumidor no cenário brasileiro, apesar dos esforços das instituições de defesa dos consumidores.

A vulnerabilidade neuropsicológica, por sua vez, é resultado dos estímulos causados pela propaganda e publicidade, a fim de despertar os sentidos do consumidor e incentivar o consumo.

\footnotetext{
${ }^{36}$ MIRAGEM, Bruno. Curso de direito do consumidor. 6. ed. São Paulo: Revista dos Tribunais, 2016. p. 128.

${ }^{37}$ MORAES, Paulo Valério Dal Pai. Código de defesa do consumidor: o princípio da vulnerabilidade no contrato, na publicidade, nas demais práticas comerciais: interpretação sistemática do direito. Porto Alegre: Livraria do Advogado, 2009. p. 141-203.
} 
A vulnerabilidade econômica e social é fruto da disparidade de forças entre consumidores e agentes econômicos, que possuem mais condições de impor sua vontade.

A vulnerabilidade ambiental está ligada aos prejuízos que o consumo acarreta ao meio ambiente, e cujas informações nem sempre são repassadas ao consumidor, que, refém do consumo, torna-se poluidor sem saber.

Por último, o doutrinador aborda a vulnerabilidade tributária, que é resultado dos tributos decorrentes da relação de consumo, que são debitados nas contas do consumidor.

A divisão do doutrinador não é unanimidade entre a doutrina, uma vez que grande parte adota a classificação de Claudia Lima Marques, dividindo a vulnerabilidade em técnica, jurídica e fática ${ }^{38}$ (a vulnerabilidade fática assemelha-se à vulnerabilidade econômica descrita por Moraes).

Ao abrir o leque de possibilidades e espécies de vulnerabilidade, a doutrina aumenta o campo de incidência do Direito do Consumidor, ao permitir a utilização de conceitos cada vez mais abrangentes para determinar os sujeitos que estarão sob sua proteção. ${ }^{39}$

\footnotetext{
${ }^{38}$ BENJAMIN, Antônio Herman V.; MARQUES, Claudia Lima; BESSA, Leonardo Roscoe. Manual de Direito do Consumidor. 4. ed. São Paulo: Revista dos Tribunais, 2012. p. 94-103.

${ }^{39}$ A respeito do conceito de vulnerabilidade e sua aplicação, ver: MARQUES, Claudia Lima. Contratos no código de defesa do consumidor: o novo regime das relações contratuais. 7. ed. São Paulo: Revista dos Tribunais, 2014; PASQUALOTTO, Adalberto. Reflexões na frente do espelho: memória e autocrítica aos 25 anos. In: MIRAGEM, Bruno; MARQUES, Claudia Lima; OLIVEIRA, Amanda Flávio de (Coord.). 25 anos do código de defesa do consumidor: trajetórias e perspectivas. São Paulo: Revista dos Tribunais, 2016. p. 15-32.
} 
Percebe-se, portanto, que o Direito do Consumidor teve uma grande evolução na conceituação da vulnerabilidade. Quando da entrada em vigor do Código de Defesa do Consumidor, o conceito de vulnerabilidade ainda era impreciso, e voltava-se predominantemente às pessoas físicas, confundindo-se fortemente com a hipossuficiência.

Nesses 25 anos de vigência, no entanto, houve uma significativa evolução do conceito, abrangendo um número cada vez maior de situações e protegendo mais consumidores em suas relações de consumo.

\section{NECESSIDADE DE DIÁLOGO ENTRE O DIREITO DO TRABALHO E O DIREITO DO CONSUMIDOR}

Tanto o Direito do Trabalho quanto o Direito do Consumidor foram criados pensando em minimizar as desigualdades entre as partes da relação.

São direitos de cunho protetivo, em que uma das partes é visivelmente mais fraca que a outra, necessitando de uma proteção maior a fim de que, no exercício de seus direitos, a desigualdade seja minimizada.

Trabalhador e consumidor são claramente vulneráveis, vendo-se compelidos, muitas vezes, a situações desagradáveis, vexatórias, humilhantes, desvantajosas e mesmo perigosas em razão de sua posição na relação.

Há pouca - ou nenhuma - diferença entre a posição de vulnerabilidade de um consumidor que assina um contrato de adesão com uma empresa fornecedora de energia elétrica ou um trabalhador que assina um contrato de trabalho padrão, em que não há negociação a respeito de suas cláusulas, mas tão somente aceitação das condições impostas pelo empregador. 
Ambos contratam em razão de premente necessidade, sujeitando-se à vontade do mais forte para que tenham suas necessidades básicas atendidas.As normas protetivas, porém, nos dois casos, trilharam caminhos inversos. O Direito do Consumidor foi expansionista no conceito de vulnerabilidade, alcançando uma gama cada vez maior de sujeitos sob sua proteção. O Direito do Trabalho, entretanto, restringe cada vez mais o conceito de subordinação, não se adequando às novas realidades e deixando muitos trabalhadores sem poder recorrer na busca de seus direitos.

\section{CONSIDERAÇÕES FINAIS}

Demonstrados os rumos tomados pelas relações que dizem respeito tanto do Direito do Trabalho quanto do Direito do Consumidor, verifica-se que tais ramos regulam situações análogas, mas que, diante da forma como os conceitos de subordinação e vulnerabilidade vêm evoluindo, distanciam-se cada vez mais.

Seria proveitoso que o Direito do Trabalho fizesse o caminho inverso, ampliando novamente o conceito de subordinação e aproximando-o cada vez mais da vulnerabilidade, eis que o seu objeto não é outro que não a proteção de um vulnerável.

Marques, ao abordar a vulnerabilidade, propôs um conceito que se amolda perfeitamente ao trabalhador em suas relações com seu empregador:

Poderíamos afirmar, assim, que a vulnerabilidade é mais um estado da pessoa, um estado inerente de risco ou um sinal de confrontação excessiva de interesses identificado no mercado, é uma situação permanente ou provisória, individual ou coletiva, que fragiliza, enfraquece o sujeito de direitos, desequilibrando a relação. A vulnerabilidade não é, pois, o fundamento das regras de proteção do sujeito mais fraco, é apenas a “explicação" destas regras ou da atuação do legislador, é a técnica para 
as aplicar bem, é a noção instrumental que guia e ilumina a aplicação destas normas protetivas e reequilibradoras, à procura do fundamento da Igualdade e da Justiça equitativa. ${ }^{40}$

Essa aproximação já foi proposta em artigo recente, abordando a vulnerabilidade no Direito do Trabalho contemporâneo. Segundo o autor,

a vulnerabilidade plena do empregado é inquestionável enquanto premissa teórica do sistema normativo juslaboral. A questão é que esta premissa não mais encerra a diversidade dos fatos sociais. Assim como pode haver empregados mais ou menos vulneráveis, há trabalhadores vulneráveis fora da relação de emprego. ${ }^{41}$

Assim sendo, a proposição que se faz, ao fim do presente estudo, é que haja uma nova expansão no Direito do Trabalho, trazendo o conceito de subordinação para a realidade fática atual, e aproveitando-se de conceitos de outros ramos de Direito também protetivos, como é o caso do Direito do Consumidor e a vulnerabilidade.

Essa expansão justifica-se com o fim máximo de proteger com a lei trabalhista não só o empregado estritamente subordinado e dependente, mas também aquele que, em que pese não estar em uma relação de trabalho típica, é vulnerável e por isso merece proteção.

\section{REFERÊNCIAS}

ABRANTES, José João. Estudo sobre o código do trabalho. Coimbra: Coimbra Editora, 2004.

\footnotetext{
${ }^{40}$ MARQUES, Claudia Lima; MIRAGEM, Bruno. O novo direito privado e a proteção dos vulneráveis. São Paulo: Revista dos Tribunais, 2012. p. 117.

${ }^{41}$ DORNELES, Leandro do Amaral Dorneles de. Hipossuficiência e vulnerabilidade na teoria geral do direito do trabalho contemporânea. Revista LTR: legislação do trabalho. v. 77, n. 3. São Paulo: LTr, mar. 2013. p. 302.
} 
ALEXY, Robert. Teoria dos direitos fundamentais. Tradução Virgílio Afonso da Silva. 2. ed. São Paulo: Malheiros, 2011.

ALONSO OLEA, Manuel. Introdução ao direito do trabalho. Porto Alegre: Livraria Sulina Editora, 1969.

ARENDT, Hannah. A condição humana. 12. ed. Rio de Janeiro: Forense, 2014. ASSIS, Rui de. O poder de direcção do empregador: configuração geral e problemas actuais. Coimbra: Coimbra Editora, 2005.

ÁVILA, Humberto. Teoria dos princípios: da definição à aplicação dos princípios jurídicos. 6. ed. São Paulo: Malheiros, 2006.

BAGGIO, Andreza Cristina. O direito do consumidor brasileiro e a teoria da confiança. São Paulo: Revista dos Tribunais, 2012.

BARASSI, Ludovico. Tratado de derecho del trabalho. Buenos Aires: Editorial Alfa, 1953.

BARBOSA, Lívia; PORTILHO, Fátima; VELOSO, Letícia (Org.). Consumo: cosmologias e sociabilidades. Rio de Janeiro: Edur, 2009.

BAUMAN, Zygmunt. Vida para consumo: a transformação das pessoas em mercadorias. Tradução Carlos Alberto Medeiros. Rio de Janeiro: Jorge Zahar Ed., 2008.

BENJAMIN, Antônio Herman V.; MARQUES, Claudia Lima; BESSA, Leonardo Roscoe. Manual de direito do consumidor. 4. ed. São Paulo: Revista dos Tribunais, 2012.

BESSA, Leonardo Roscoe. Aplicação do código de defesa do consumidor análise crítica da relação de consumo. Brasília: Brasília Jurídica, 2007.

CARRION, Valentin. Comentários à Consolidação das Leis Trabalhistas. 40. ed. São Paulo: Saraiva, 2015.

CATHARINO, José Martins. Compêndio de direito do trabalho. 3. ed. São Paulo: Saraiva, 1982. V. 1.

CAVALIERI FILHO, Sergio. Programa de Direito do Consumidor. São Paulo: Atlas, 2008. 
CESARINO JUNIOR, Antonio Ferreira. Natureza jurídica do contrato individual de trabalho. Rio de Janeiro: A. Coelho Branco, 1938.

CHAZAL, Jean-Pascal. Vulnérabilité et droit de la consommation. In: COHET-CORDEY, Frédérique. Vulnérabilité et droit: le développement de la vulnérabilité et ses enjeux en droit. Grenoble: Presses Universitaires de Grenoble, 2000. p. 243-264.

DEVEALI, Mario L. Lineamentos de derecho del trabajo. 2. ed. Buenos Aires: Tipográfica Editora Argentina, 1953.

DIAS, Lucia Ancona Lopez de Magalhães. Publicidade e direito. 2. ed. São Paulo: Revista dos Tribunais, 2013.

DORNELES, Leandro do Amaral Dorneles de. Hipossuficiência e vulnerabilidade na teoria geral do direito do trabalho contemporânea. Revista LTR: Legislação do Trabalho, São Paulo, v. 77, n. 3, p. 293-303, mar. 2013.

DUQUE, Marcelo Schenk. Direito privado e Constituição: drittwirkung dos direitos fundamentais, construção de um modelo de convergência à luz dos contratos de consumo. São Paulo: Revista dos Tribunais, 2013. FANTINI, Oddone. Legislazione Corporativa del Lavoro. Milano: Francesco Vallardi, 1938. FAVIER, Yann. A inalcançável definição de vulnerabilidade aplicada ao Direito: abordagem francesa. Revista de Direito do Consumidor, São Paulo, v. 85, p. 15 et seq., jan. 2013, DTR2013\492.

FERRAJOLI, Luigi. Por uma teoria dos direitos e dos bens fundamentais. Tradução Alexandre Salim, Alfredo Copetti Neto, Daniela Cadermatori, Hermes Zaneti Júnior, Sérgio Cadermatori. Porto Alegre: Livraria do Advogado, 2011. FREITAS, Juarez. A interpretação sistemática do Direito. 5. ed. São Paulo: Malheiros, 2010.

FRONTINI, Paulo Salvador. Acesso ao consumo. In: GOZZO, Débora (Coord.). Informação e direitos fundamentais: a eficácia horizontal das normas constitucionais. São Paulo: Saraiva, 2012. p. 203-225.

GIL, Antônio Carlos. Métodos e técnicas de pesquisa social. 6. ed. São Paulo: Atlas, 2008. 
GOMES, Luiz Flávio; MAZZUOLI, Valerio de Oliveira. Comentários à Convenção Americana sobre Direitos Humanos: Pacto de San José da Costa Rica. 4. ed. São Paulo: Revista dos Tribunais, 2013.

GOMES, Orlando. Questões de direito do trabalho. São Paulo: LTr, 1974.

GRINOVER, Ada Pellegrini; et. al. Código Brasileiro de Defesa do Consumidor: comentado pelos autores do anteprojeto. 6. ed. Rio de Janeiro: Forense Universitária, 2000.

HARVEY, David. Condição pós-moderna. 24. ed. São Paulo: Loyola Jesuítas, 2013.

JAYME, Erik. Direito Internacional Privado e Cultura Pós-Moderna. Cadernos do Programa de Pós-Graduação em Direito - PPGDir./UFRGS, Porto Alegre, v. 1, n. 1, p. 105-114, mar. 2003. Identité culturelle et intégration: le droit international privé postmoderne. Recueil des Cours, 251, 1995.

KROTOSCHIN, Ernesto. Instituiciones de derecho del trabajo. 2. ed. Buenos Aires: Depalma, 1968.

LA CUEVA, Mario de. Derecho mexicano del trabajo. 4. ed. México: Editorial Porrua, 1954. Tomo I.

LACERDA, Dorval de. A renúncia no direito do trabalho. 2. ed. São Paulo: Max Limonad, 1944.

LEITE, Carlos Henrique Bezerra. Curso de Direito do trabalho. 6. ed. São Paulo: Saraiva, 2015.

LEITE, Carlos Henrique Bezerra; MIRANDA, Jedson Marcos dos Santos. Direito humano fundamental ao emprego: subordinação jurídica e o novel artigo $6^{\circ}$ da CLT. Revista IOB Trabalhista e Previdenciária, São Paulo, v. 273, p. 9-16, 2002.

MALLET, Estêvão. A subordinação como elemento do contrato de trabalho. Revista da Faculdade de Direito da Universidade de São Paulo, São Paulo, v. 106/107, p. 217-245, jan./dez. 2011/2012.

MALTEZ, Rafael Tocantins. Direito do consumidor e publicidade: análise jurídica e extrajurídica da publicidade subliminar. Curitiba: Juruá, 2011. 
MARQUES, Claudia Lima (Coord.). Diálogo das fontes: do conflito à coordenação de normas do direito brasileiro. São Paulo: Revista dos Tribunais, 2012a. MARQUES, Claudia Lima. A proteção dos consumidores em um mundo globalizado: studium generale sobre o consumidor como homo novus. Revista de Direito do Consumidor, São Paulo, v. 85, p. 25 et. seq., jan. 2013, DTR\2013\484. . Comentários ao código de defesa do consumidor. São Paulo: Revista dos Tribunais, 2012b.

. Contratos no código de defesa do Consumidor: o novo regime das relações contratuais. 7. ed. São Paulo: Revista dos Tribunais, 2014.

Normas de proteção do consumidor (especialmente, no comércio eletrônico) oriundas da União Européia e o exemplo de sua sistematização no Código Civil Alemão de 1896 - notícia sobre as profundas modificações no BGB para incluir a figura do consumidor. Revista de Direito Privado, São Paulo, v. 4, p. 50 et seq., out. 2000, DTR12000\817.

O "diálogo das fontes" como método da nova teoria geral do direito: um tributo a Erik Jayme. In: MARQUES, Claudia Lima (Coord.). Diálogo das fontes: do conflito à coordenação de normas do direito brasileiro. São Paulo: Revista dos Tribunais, 2012c. p. 17-66.

. Proteção do consumidor no âmbito do comércio eletrônico. Revista da Faculdade de Direito da Universidade Federal do Rio Grande do Sul. Porto Alegre, v. 23, p. 47-84, 2003.

MARQUES, Claudia Lima; MIRAGEM, Bruno (Orgs.). Direito do consumidor: vulnerabilidade do consumidor e modelos de proteção. São Paulo: Revista dos Tribunais, 2011. (Coleção doutrinas essenciais, v. 2).

MARQUES, Claudia Lima; MIRAGEM, Bruno. O direito fundamental de proteção do consumidor e os 20 anos da Constituição: fundamentos e desafios do direito do consumidor brasileiro contemporâneo. In: MARTINS, Ives Gandra; REZEK, Francisco (Coord.). Constituição Federal: avanços, contribuições e modificações no processo democrático brasileiro. São Paulo: Revista dos Tribunais, 2008. p. 644-667. 
REZEK, Francisco (Coord.). O novo direito privado e a proteção dos vulneráveis. São Paulo: Revista dos Tribunais, 2012.

MIRAGEM, Bruno. Curso de direito do consumidor. 6. ed. São Paulo: Revista dos Tribunais, 2016.

MORAES FILHO, Evaristo de. Do contrato de trabalho como elemento da empresa. São Paulo: LTr, 1993.

MORAES, Paulo Valério Dal Pai. Código de defesa do consumidor: o princípio da vulnerabilidade no contrato, na publicidade, nas demais práticas comerciais: interpretação sistemática do direito. Porto Alegre: Livraria do Advogado, 2009. MURARI, Marlon Marcelo. A subordinação como elemento da relação de emprego: conceito, distinções e fundamento jurídico. Disponível em: $<\mathrm{http}: / /$ www.linhasjuridicas.com.br/artigo.php?op=ver\&id_artigo=55>. Acesso em: 5 ago. 2013.

NASCIMENTO, Amauri Mascaro. Curso de direito do trabalho: história e teoria geral do direito do trabalho: relações individuais e coletivas do trabalho. 13. ed. São Paulo: Saraiva, 1997.

NISHIYAMA, Adolfo Mamoru. A proteção constitucional do consumidor. 2. ed. São Paulo: Atlas, 2010.

NISHIYAMA, Adolfo Mamoru; DENSA, Roberta. A proteção dos consumidores hipervulneráveis: os portadores de deficiência, os idosos, as crianças e os adolescentes. Revista de Direito do Consumidor, São Paulo, v. 76, p. 13-45, out./dez. 2010.

OLIVEIRA VIANA, José Francisco de. Contratos de trabalho, de empreitada e de mandato. Boletim do Ministério do Trabalho, Industria e Commercio. Rio de Janeiro, n. 33/34, maio/jun. 1937.OLIVEIRA, Cinthia Machado de; DORNELES, Leandro do Amaral Dorneles de. Direito do trabalho. 2. ed. Porto Alegre: Verbo Jurídico, 2013. PAIVA, Rafael Augusto Moura. Repensando o "ser" consumidor. Revista de Direito do Consumidor, São Paulo, v. 88, p. 103144, jul./ago. 2013.

PASQUALOTTO, Adalberto. Os efeitos obrigacionais da publicidade no Código de Defesa do Consumidor. São Paulo: Revista dos Tribunais, 1997. 
PASQUALOTTO, Adalberto. Reflexões na frente do espelho: memória e autocrítica aos 25 anos. In: MIRAGEM, Bruno; MARQUES, Claudia Lima; OLIVEIRA, Amanda Flávio de (Coord.). 25 anos do código de defesa do consumidor: trajetórias e perspectivas. São Paulo: Revista dos Tribunais, 2016. p. 15-32.

PASQUALOTTO, Adalberto; ALVAREZ, Ana Maria Blanco Montiel (Org.). Publicidade e proteção da infância. Porto Alegre: Livraria do Advogado, 2014. PASQUALOTTO, Adalberto; AZAMBUJA, Mariana Menna Barreto. A comédia da publicidade: entre a sátira e o politicamente correto. Revista de Direito do Consumidor, São Paulo, v. 96, p. 89-101, nov. 2014.

PEREZ BOTIJA, Eugenio. Curso de derecho del trabajo. Madrid: Editorial Tecnos, 1948.

PICK, Marielle. Le droit du travail est-il le droit des vulnérables. In: COHET-CORDEY, Frédérique. Vulnérabilité et droit: le développement de la vulnérabilité et ses enjeux en droit. Grenoble: Presses Universitaires de Grenoble, 2000. p. 277-294.

PORTO, Lorena Vasconcelos. A subordinação no contrato de emprego: desconstrução, reconstrução e universalização do conceito jurídico. 2008. 353 f. Dissertação (Mestrado) - Pontifícia Universidade Católica de Minas Gerais, Belo Horizonte, 2008.

RODRIGUES, Bruno Alves. Novo paradigma de subordinação na relação de emprego. Revista do Tribunal Regional do Trabalho da $3^{\underline{a}}$ Região, Belo Horizonte, v. 39, n. 69, p. 57-74, jan./jun. 2004.

RODRIGUEZ, Américo Plá. Princípios de direito do trabalho. São Paulo: LTr, 1996.

ROMITA, Arion Sayão. Conceito objetivo de subordinação. Arquivos do Ministério da Justiça, Rio de Janeiro, ano 35, n. 148, p. 75-87, out./dez. 1978.

ROSANVALLON, Pierre. La société des égaux. Paris: Seuil, 2011.

SCHMITT, Cristiano Heineck. Consumidores hipervulneráveis: a proteção do idoso no mercado de consumo. São Paulo: Atlas, 2014. p. 202. 
SCHMITT, Cristiano Heineck. A "hipervulnerabilidade" do consumidor idoso. Revista de Direito do Consumidor, São Paulo, v. 70, p. 139-171, abr./jun. 2009.

SILVA, Antônio Álvares da. Convenção coletiva do trabalho perante o direito alemão. Rio de Janeiro: Forense, 1981.

SILVA, Otávio Pinto e. Subordinação, autonomia e parassubordinação nas relações de trabalho. São Paulo: LTr, 2004.

STANDER, Célia Regina Camachi. Fraude por meio de cooperativa e de constituição de pessoa jurídica por trabalhadores. Revista da Escola da Magistratura do Tribunal Regional do Trabalho da $2^{\underline{a}}$ Região, São Paulo, a. I, n. 1, p. 105, set. 2006 .

SÜSSEKIND, Arnaldo et al. Instituições de direito do trabalho. 21. ed. São Paulo: LTr, 2003. V. 1.

VILHENA, Paulo Emílio Ribeiro de. Relação de emprego: estrutura legal e supostos. 2. ed. São Paulo: LTr, 1999.

WADDINGTON, Lisa. Reflections on the Protection of "Vulnerable" Consumers under EU Law. Maastricht Faculty of Law Working Paper 2013/2. Disponível em: <http://www.maastrichtuniversity.nl/web/file?uuid=603b9c8742c1-436a-8fcd-840cf08c0cca\&owner=2bc43a34-ef3a-4380-9c60-7badc43b5483> . Acesso em: 10 dez. 2013.

XAVIER, José Tadeu Neves. Os limites da atuação publicitária na condução de comportamentos sociais: o valor da ética no controle jurídico da publicidade. Revista de Direito do Consumidor, São Paulo: Revista dos Tribunais, ano 21, v. 81, p. 117-143, jan./mar. 2012.

Recebido em: 22/7/2016

Revisões requeridas em: 19/8/2016

Aprovado em: 19/8/2016 